$\mathbb{T}$ periodica polytechnica

Civil Engineering

$58 / 2(2014) 155,171$

doi: $10.3311 /$ PPci.7550

http://periodicapolytechnica.org/ci

Creative Commons Attribution (1)

RESEARCH ARTICLE

\section{An efficient hybrid particle swarm strategy, ray optimizer, and harmony search algorithm for optimal design of truss structures}

Ali Kaveh / Seyed Mohammad Javadi

Received 2013-12-12, accepted 2014-03-10

\begin{abstract}
In this paper a metaheuristic algorithm composed of particle swarm, ray optimization, and harmony search (HRPSO) is presented for optimal design of truss structures. This algorithm is based on the particle swarm ray origin making is used to update the positions of the particles, and for enhancing the exploitation of the algorithm the harmony search is utilized. Numerical results demonstrate the efficiency and robustness of the HRPSO method compared to some standard metaheuristic algorithms.
\end{abstract}

\section{Keywords}

Particle swarm optimization · Ray optimization · Harmony search $\cdot$ Truss structures design $\cdot$ Size optimization

\section{Ali Kaveh}

Centre of Excellence for Fundamental Studies in Structural Engineering, School of Civil Engineering, Iran University of Science and Technology, Tehan-16, Iran e-mail: alikaveh@iust.ac.ir

\section{Seyed Mohammad Javadi}

Centre of Excellence for Fundamental Studies in Structural Engineering, School of Civil Engineering, Iran University of Science and Technology, Tehan-16, Iran

\section{Introduction}

Metaheuristic algorithms have become powerful tools for optimizing many problems in different fields of engineering. Examples of such algorithms are GA algorithm [1], Particle Swarm Optimization algorithm [2, 3], Ant Colony Optimization algorithm [4], Charged System Search [5] Ray Optimization [6] and many other algorithms. Apart from these basic algorithms, researchers are still striving to balance the exploration and exploitation abilities of the metaheuristic algorithms, Some examples of these are a hybrid PSO with the passive congregation (PSOPC) [7], a hybrid PSO with ACO and HS utilized for controlling the variable constraint (HPSACO) [8], a hybrid method ANGEL, which combined ant colony optimization (ACO), genetic algorithm (GA), and local search strategy (LS) [9, 10], among others

Recently, structural optimization has become one of the most popular fields of optimization science. Different algorithms have been employed for structural optimization including Genetic Algorithms [11], Ant Colony Optimization [12], Particle Swarm Optimizer [13 14], Harmony Search [15], Big Bang-Big Crunch [16] Structural optimization has been studied in three major groups as: (a) Size optimization (b) Topology optimization (c) Shape optimization.

In this paper, the mixed particle swarm ray optimization and harmony search is applied to the size optimization of truss structures. In this algorithm, PSO acts as the main engine of the algorithm, RO boost the movement vector of the particles and HS enhances the local search for better exploitation.

\section{A brief introduction to the PSO, HS and RO}

\subsection{Particle swarm optimization}

Particle swarm optimization (PSO) is a simple and effective algorithm for optimizing a wide range of functions. Conceptually, it seems to lie somewhere between genetic algorithm and evolutionary programming [2] The PSO uses the real-number randomness and the global communication among the swarm particles. In this sense, it is also easier to implement as there is no encoding or decoding of the parameters into binary strings as in genetic algorithms [17]. On each iteration, the swarm is 
updated by the following equations [3, 18]:

$$
\begin{gathered}
V_{i}^{k+1}=\omega V_{i}^{k}+c_{1} r_{1}\left(P_{i}^{k}-X_{i}^{k}\right)+c_{2} r_{2}\left(P_{g}^{k}-X_{i}^{k}\right) \\
X_{i}^{k+1}=X_{i}^{k}+V_{i}^{k+1}
\end{gathered}
$$

where $P_{i}$ is the best previous position of the $i$ th particle and $P_{g}$ is the best position of the particles which ever found. $\omega$ is an inertia weight to control the influence of the previous velocity, $c_{1}$ and $c_{2}$ are two acceleration constants and $r_{1}$ and $r_{2}$ are two random numbers uniformly distributed in the range of $(0,1)$. The flowchart of the PSO is shown in Fig. 1.

\subsection{Harmony search}

The Harmony search algorithm was conceptualized using the musical process of searching for a perfect state of harmony. Musical performances seek to find pleasing harmony as determined by an aesthetic standard, just as the optimization process seeks to find a global solution as determined by an objective function. The pitch of each musical instrument determines the aesthetic quality [19].

Fig. 2 shows the optimization procedure of the HS algorithm, which consists of the following steps [15]:

Step 1: Initialize the optimization problem and the algorithm parameters such as specification of each decision variable, possible value range for each decision variable, harmony memory size (HMS), harmony memory considering rate (HMCR), pitch adjusting rate (PAR), harmony memory (HM) and termination criterion.

Step 2: Improvise a new harmony from the HM. A new harmony vector is generated from the HM based on memory considerations rate (HMCR), pitch adjustments and randomization (PAR). The HMCR sets the rate of choosing one value from the historic values stored in the HM, and (1-HMCR) sets the rate of randomly choosing one value from the possible range of values. While the HMCR varies between 0 and 1, the pitch adjusting process is performed only after a value is chosen from the HM. The value (1-PAR) sets the rate of doing nothing. If the pitch adjustment decision for $x_{i}$ is yes then

$$
x_{i}^{\prime} \leftarrow x_{i}^{\prime}+b w \cdot u(-1,1)
$$

where $b w$ is an arbitrary distance bandwidth for the continuous design variable and $u(-1,1)$ is a uniform distribution between -1 and 1 The HMCR and PAR parameters introduced in the harmony search help the algorithm to find globally and locally improved solutions, respectively [19].

Step 3: Update the HM. In Step 4, if the New Harmony is better than the worst harmony in the HM, the New Harmony is included in the HM and the existing worst harmony is excluded from the HM. The HM is then sorted by the value of the objective function.

Step 4: Repeat Steps 2 and 3 until the termination criterion is satisfied. The computations are terminated when the termination criterion is satisfied. Otherwise, steps 2 and 3 are repeated.

\subsection{Ray optimization}

Ray optimization (RO) is recently developed by Kaveh and Khayatazad [6] This method is inspired by the transition of ray from one medium to another from physics and uses the Snell's refraction law of the light. The transition of the ray is utilized for finding the global or near-global solution.

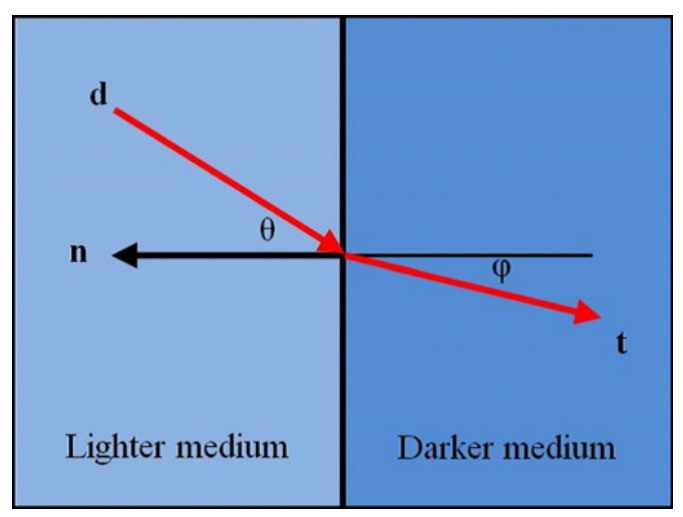

Fig. 3. Incident and refracted rays and their specifications.

The pseudo-code of RO is presented in the following [20]:

Level 1: Scattering and evaluation

Step 1. Initialization. Initialize the parameter of the RO. Initialize an array of agents with random positions. According to the number and type of groups that belong to the agent positions, make an arbitrary array of the velocity vector. Each of these two or three variable velocity vectors should be a normalized vector.

Step 2. Evaluation. For each agent evaluate the value of the goal function in the current position. Save the position of the best agent as the global best. Save the position of each agent as its local best.

Level 2: Movement vector and motion refinement

Step 1. Movement vector. Add the solution vectors with the corresponding movement vector.

Step 2. Motion refinement. If any agent violates a variable boundary, refine its movement vector. After motion refinement and evaluation of the goal function, again the so-far best agent at this stage is selected as the global best, and for each agent, the so-far best position by this stage (belonging to itself) is selected as its local best.

Level 3: Origin making and converging

Step 1. Origin making. Find the origin of the each agent.

Step 2. Converging. Calculate the new movement vector for each agent.

Level 4: Finish or redoing. Repeat the optimization process until a terminating criteria is satisfied.

\section{Mixed particle swarm, ray optimization, and harmony search algorithm}

Compared to other algorithms, PSO has a versatility to be hybridized with other metaheuristics and simple to implement. However, standard PSO has some infirmity, Shi and Eberhart [18] introduced a parameter known as the inertia weight into 


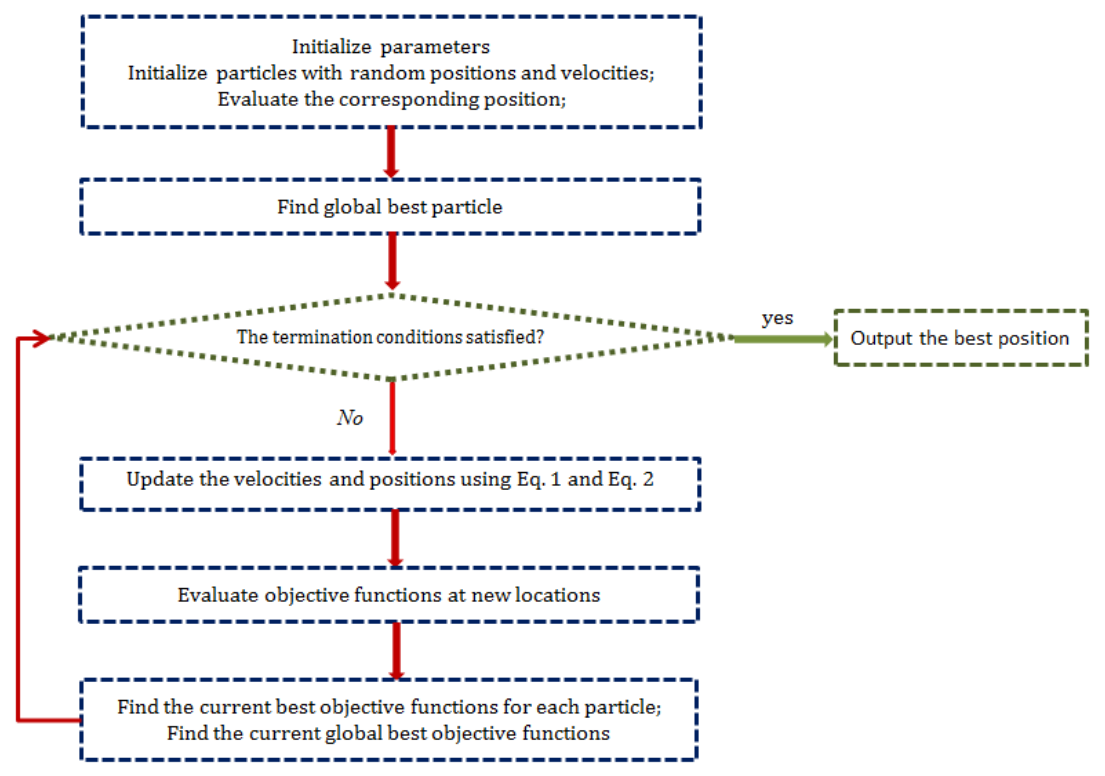

Fig. 1. Flowchart of the PSO.

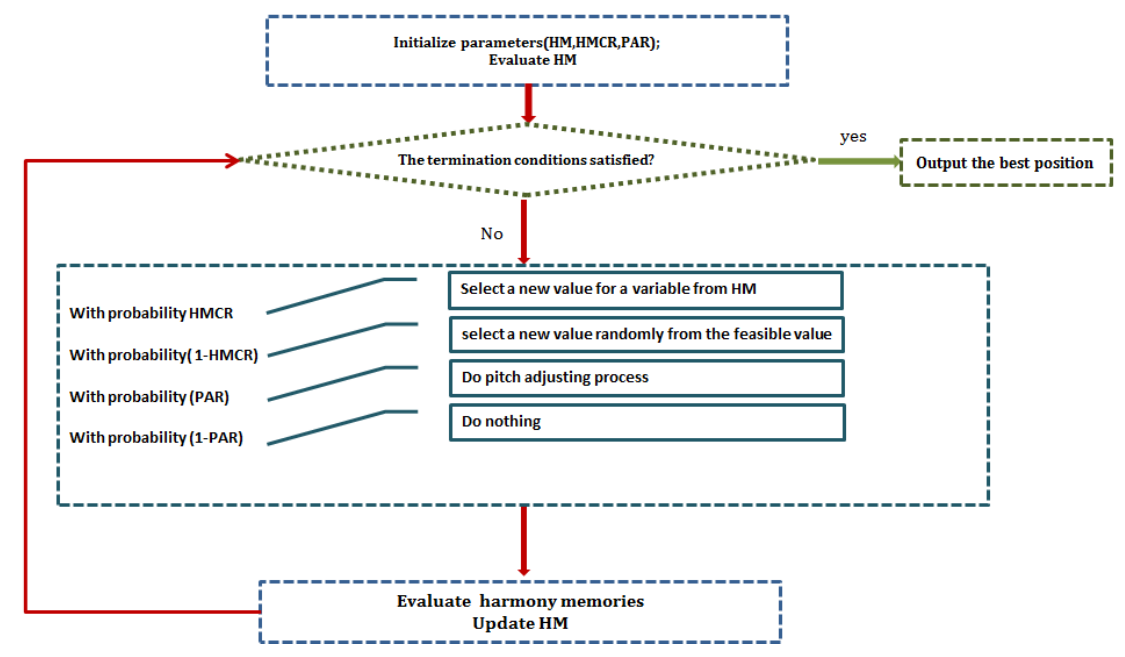

Fig. 2. Flowchart of the HS. 
the original particle swarm optimizer, to decrease the computational time and improve ability in finding the global optimum. However, there is no information sharing among individuals except that global best broadcasts the information to the other individuals. Therefore, the population may lose diversity and is more likely to confine the search around local minima if committed too early in the search to the global best found so far $\mathrm{He}$ et al. [7] introduced a new PSO with the passive congregation (PSOPC), by introducing the passive congregation, information can be transferred among individuals that will help individuals to avoid misjudging information and becoming trapped by poor local minima. Therefore in the PSOPC there are parameters such as $c_{1}, c_{2}$ and $c_{3}$ with each of them having an important role on the performance of the algorithm.

On the other hand Ray optimization algorithm has an origin making part which has an important role in this algorithm. In the RO first the point to which each particle moves must be determined. This point is named origin and it is specified by:

$$
O_{i}^{k}=\frac{(i t e+k) \cdot G B+(\text { ite }-k) \cdot L B_{i}}{2 \cdot i t e}
$$

Where $O_{i}^{k}$ is the origin of the $i$ th agent or particle for the $k$ th iteration, ite is the total number of iterations of the optimization process, $G B$ and $L B_{i}$ are the global best and local best of the $i$ th agent, respectively [6]. In HRPSO ray origin making is used to update the positions of the particles by the following equations:

$$
V_{i}^{k+1}=\omega V_{i}^{k}+\operatorname{rand} . O_{i}^{k}
$$

Thus in this algorithm. Parameters such as $c_{1}, c_{2}$ and $c_{3}$ in standard PSO and PSO with the passive congregation (PSOPC) substitute with origin making relation which is independent from parameter tuning. In this equation the inertia weight considered as a decreasing function of time which gradually decrease from 1 by each iteration and rand is a random number between 0 and 1.

On the other hand for enhancing the exploitation, the HS introduces a parameter named pitch adjustment which helps the algorithm find locally improved solutions [19] so the PAR used to reinforce the HRPSO for better local search.

By these techniques, there is no dependency on the parameters like as $c_{1}, c_{2}$ and $c_{3}$ in the PSO and PSOPC. The flow chart of the HRPSO is shown in Fig. 4 .

\section{STRUCTURAL OPTIMIZATION PROBLEM}

The mathematical formulation of this optimization problem can be expressed as:

$$
\begin{aligned}
& \text { minimize } W(\{X\})=\sum_{i=1}^{n} \gamma_{i} A_{i} L_{i}(x) \\
& \text { subject to : } \delta_{\text {min }} \leq \delta_{i} \leq \delta_{\text {max }}, i=1,2, \ldots, m \\
& \sigma_{\text {min }} \leq \sigma_{i} \leq \sigma_{\text {max }}, i=1,2, \ldots, n \\
& \sigma_{i}^{b} \leq \sigma_{i} \leq 0, i=1,2, \ldots, n s \\
& A_{\text {min }} \leq A_{i} \leq A_{\text {max }}, i=1,2, \ldots, n g
\end{aligned}
$$

Where $W(\{X\})$ is the weight of the structure; $m$ is the number of nodes; $n$ is the number of members making up the structure; $n s$ is the number of compression elements; $n g$ is the number groups (number of design variables); $\gamma_{i}$ is the material density of member $i ; L_{i}$ is the length of member $i ; A_{i}$ is the cross-sectional area of member $i$ chosen between $A_{\min }$ and $A_{\max }$; min is the lower bound and max is the upper bound; $\sigma_{i}$ and $\delta_{i}$ are the stress and nodal deflection, respectively; $\sigma_{i}^{b}$ is the allowable buckling stress in member $i$ when it is in compression.

The penalty approach is used for constraint handling, i.e., if the constraints are not violated, the penalty will be zero; otherwise, the value of the penalty is calculated by dividing the violation of the allowable limit to the limit itself.

\section{DESIGN EXAMPLES}

In this section, four truss structures are optimized utilizing the present algorithm. These optimization examples consist of a 25 bar space truss subjected to two load conditions, a 72 bar space truss subjected to two load conditions, a 120 bar dome space truss subjected to a single load condition and a 200 bar planar truss subjected to three load conditions.

In the proposed algorithm, the maximum number of iterations is set equal to 400 , a population of 40 particles is used for the first example, a population of 60 particles is utilized for the second example and a population of 90 particles is employed for two last examples. The maximum velocity is set as the difference between the upper and lower bounds, which guarantees that the particles rationally survey the search space and pitch adjusting rate (PAR) consider as 0.2. These truss structures are analyzed using the finite element method (FEM).

\subsection{A 25-bar space truss}

The topology and nodal numbers of a 25-bar spatial truss structure are shown in Fig. 5. This structure has been size optimized by many researchers and the results are compared. In these studies, the material density was $0.1 \mathrm{lb} / \mathrm{in}^{3}$ $\left(2767.990 \mathrm{~kg} / \mathrm{m}^{3}\right)$ and modulus of elasticity was $10,000 \mathrm{ksi}$ (68950 MPa), Twenty five members are categorized into eight groups, as shown in Tab. 1 Designs for a multiple load case are performed as shown in Tab. 2. The truss members are subjected to the compressive and tensile stress limitations shown in Tab. 3

In addition, maximum displacement limitations of \pm 0.35 in $(8.89 \mathrm{~mm})$ are imposed on every node in every direction. The 


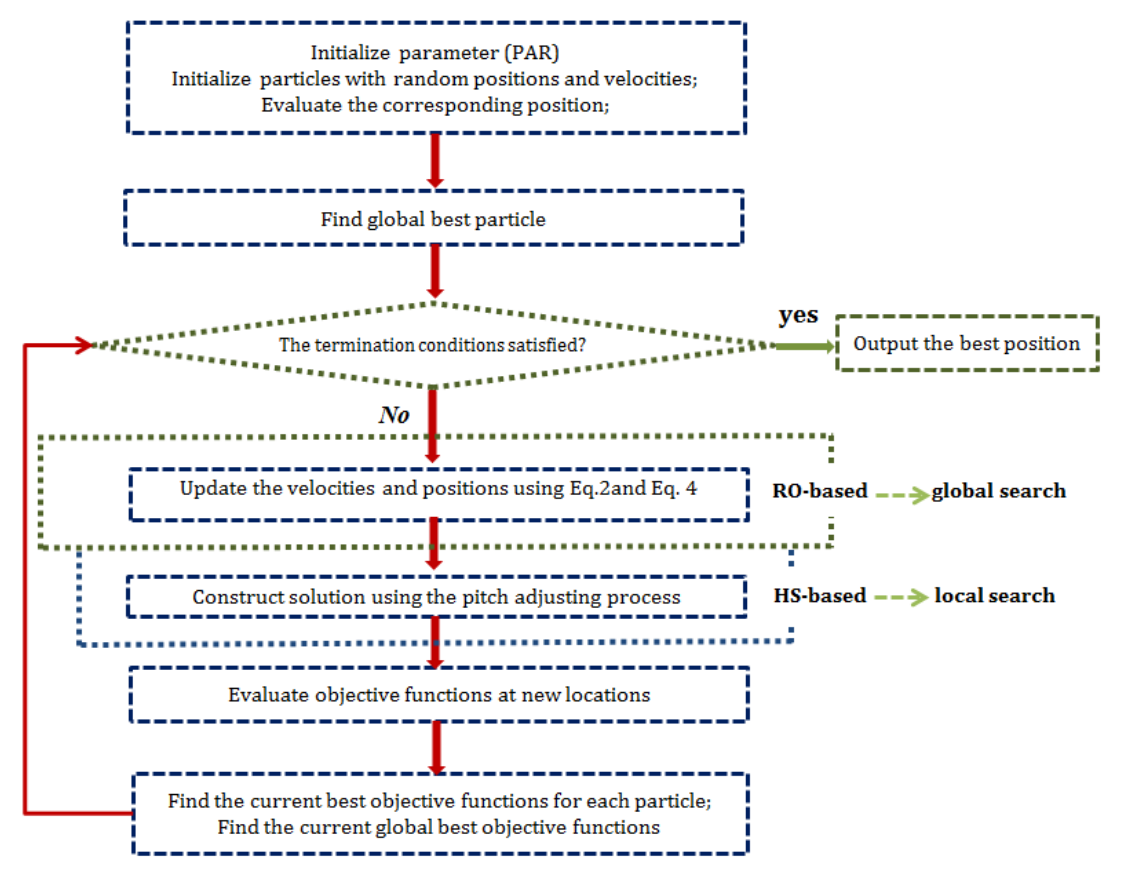

Fig. 4. Flowchart of the HRPSO.

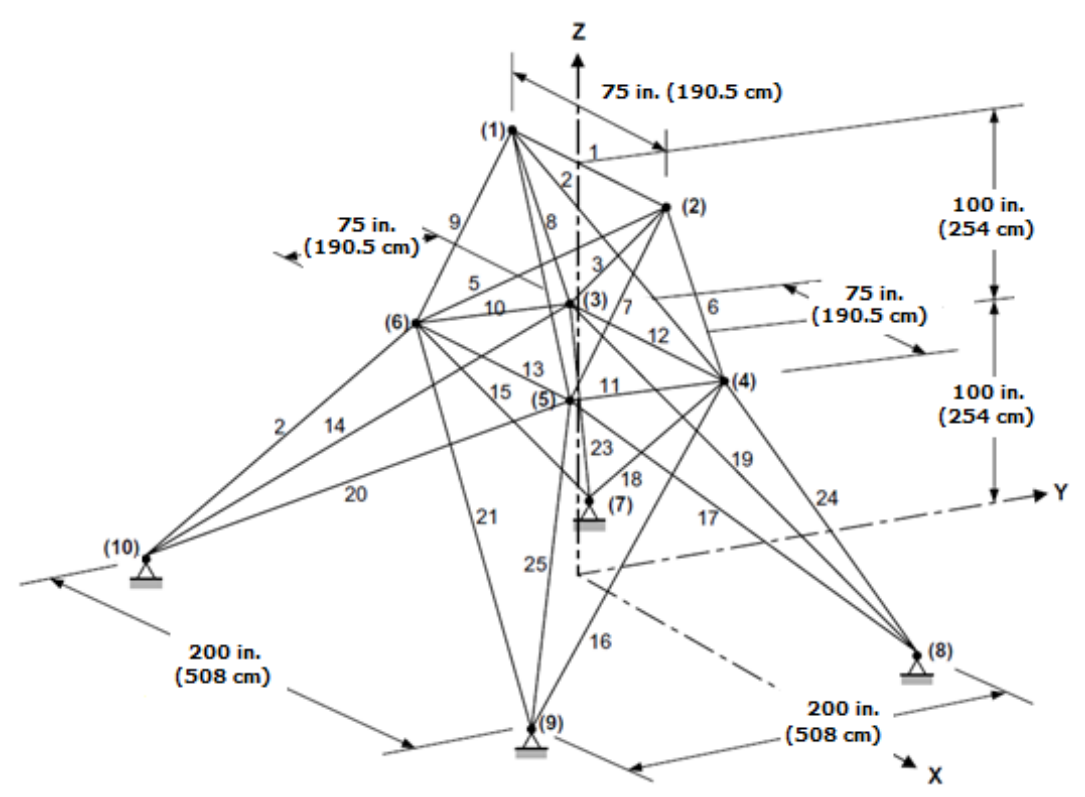

Fig. 5. A 25-bar spatial truss.

Tab. 1. Element information for the 25-bar spatial truss.

\begin{tabular}{cccccccc}
\hline \multicolumn{7}{c}{ Element group number } \\
\hline 1 & 2 & 3 & 4 & 5 & 6 & 7 & 8 \\
\hline $1 ;(1,2)$ & $2:(1,4)$ & $6:(2,4)$ & $10:(6,3)$ & $12:(3,4)$ & $14:(3,10)$ & $18:(4,7)$ & $22:(10,6)$ \\
\hline & $3:(2,3)$ & $7:(2,5)$ & $11:(5,4)$ & $13:(6,5)$ & $15:(6,7)$ & $19:(3,8)$ & $23:(3,7)$ \\
\hline & $4:(1,5)$ & $8:(1,3)$ & & & $16:(4,9)$ & $20:(5,10)$ & $24:(4,8)$ \\
\hline & $5:(2,6)$ & $9:(1,6)$ & & & $17:(5,8)$ & $21:(6,9)$ & $25:(5,9)$ \\
\hline
\end{tabular}


Tab. 2. Loading conditions for the 25-bar spatial truss.

\begin{tabular}{|c|c|c|c|c|c|c|}
\hline \multirow[t]{2}{*}{ Node } & \multicolumn{3}{|c|}{ Case1 } & \multicolumn{3}{|c|}{ Case2 } \\
\hline & $P_{X}$ & $\begin{array}{c}P_{Y} \\
\text { kips }(\mathrm{kN})\end{array}$ & $\begin{array}{c}P_{Z} \\
\text { kips }(\mathrm{kN})\end{array}$ & $\begin{array}{c}P_{X} \\
\text { kips }(k N)\end{array}$ & $\begin{array}{c}\mathrm{P}_{Y} \\
\text { kips }(\mathrm{kN})\end{array}$ & $\begin{array}{c}P_{Z} \\
\text { kips }(k N)\end{array}$ \\
\hline 1 & 0.0 & $20.0(89)$ & $\begin{array}{c}-5.0 \\
(22.25)\end{array}$ & $1.0(4.45)$ & $10(44.5)$ & $\begin{array}{c}-5.0 \\
(22.25)\end{array}$ \\
\hline 2 & 0.0 & $-20.0(89)$ & $\begin{array}{c}-5.0 \\
(22.25)\end{array}$ & 0.0 & $10(44.5)$ & $\begin{array}{c}-5.0 \\
(22.25)\end{array}$ \\
\hline 3 & 0.0 & 0.0 & 0.0 & $0.5(2.22)$ & 0.0 & 0.0 \\
\hline 6 & 0.0 & 0.0 & 0.0 & $0.5(2.22)$ & 0.0 & 0.0 \\
\hline
\end{tabular}

Tab. 3. Member stress limitation for the 25-bar spatial truss.

\begin{tabular}{cccc}
\hline & Element group & $\begin{array}{c}\text { Compressive stress } \\
\text { limitations ksi (MPA) }\end{array}$ & $\begin{array}{c}\text { Tensile stress limitations } \\
\text { Ksi }\end{array}$ \\
\hline 1 & A1 & $35.092(241.96)$ & $40.0(275.80)$ \\
\hline 2 & A2 A5 & $11.590(79.913)$ & $40.0(275.80)$ \\
\hline 3 & A6 A9 & $17.305(119.31)$ & $40.0(275.80)$ \\
\hline 4 & A10 A11 & $35.092(241.96)$ & $40.0(275.80)$ \\
\hline 5 & A12 A13 & $35.092(241.96)$ & $40.0(275.80)$ \\
\hline 6 & A14 A17 & $6.759(46.603)$ & $40.0(275.80)$ \\
\hline 7 & A18 A21 & $6.959(47.982)$ & $40.0(275.80)$ \\
\hline 8 & A22 A25 & $11.082(76.410)$ & $40.0(275.80)$ \\
\hline
\end{tabular}

minimum and maximum cross-sectional area of all members is $0.01 \mathrm{in}^{2}\left(0.06452 \mathrm{~cm}^{2}\right)$ and $3.4 \mathrm{in}^{2}\left(21.94 \mathrm{~cm}^{2}\right)$ respectively A comparison to other references with respect to the crosssectional area of each group and the final weight reached for the 25 bar space truss is shown in the Tab. 4. Fig. 6 and Fig. 7 compare the allowable existing stress and displacement constraint values of the HRPSO resulted for two different loading conditions. The comparison of the results of HRPSO with those of the HS and PSO is shown in Fig. 8 .

\subsection{A 72-bar spatial truss}

A 72-bar spatial truss shown in Fig. 9. Tab. 5 lists the values and directions of the two load cases applied to the 72 bar spatial truss. It has been size optimized by many researchers [12, 14, 16, 20, 23, 24]. In these studies, the material density and modulus of elasticity were $0.1 \mathrm{lb} / \mathrm{in}^{3}\left(2767.990 \mathrm{~kg} / \mathrm{m}^{3}\right)$ and $10,000 \mathrm{ksi}(68950 \mathrm{MPa})$, respectively. The members were subjected to the stress limits of $\pm 25 \mathrm{ksi}( \pm 172.375 \mathrm{MPa})$ and the uppermost nodes were subjected to the displacement limits of \pm 0.25 in $( \pm 0.635 \mathrm{~cm})$ in both $\mathrm{x}$ and $\mathrm{y}$ direction. In this example, two cases are considered:

Case 1: in which the minimum cross-sectional area of all members is $0.1 \mathrm{in}^{2}\left(0.6452 \mathrm{~cm}^{2}\right)$ and Case 2: in which the minimum cross-sectional area of $0.01 \mathrm{in}^{2}\left(0.0645 \mathrm{~cm}^{2}\right)$ is considered. Tab. 6 shows the results for Case 1 and compares these results with those previously reported in the literature. In Case 1, the best weight of the HRPSO algorithm is $379.688 \mathrm{lb}(1689 \mathrm{~N})$. It gets the optimal solution after 153 iterations and 9180 function evaluations. The standard deviation of the HRPSO is $0.88 \mathrm{lb}$ $(3.91 \mathrm{~N})$ which is better than those of the ACO, BB-BC and RO, being 3.66, 1.912 and 1.22 respectively. Tab. 7 shows the results for Case 2, In this case, HRPSO finds the best result while other algorithms could not reach an optimum design. Comparison between the allowable and existing stress and displacement constraint values of the HRPSO for Case 2 is shown in Fig. 10 and Fig. 11, it can be deduced that the second load condition is dominant. The convergence history for this example is shown in Fig. 12

\subsection{A 120-bar dome truss}

The topology and group members of a 120-bar dome truss are shown in Fig. 13 This structure was first analyzed by Soh and Yang [25] to obtain the optimal sizing and configuration variables and then it was studied by Lee and Geem [15], Kaveh and Talatahari [8, 16] and Kaveh and Khayatazad [20]. In the example considered in these studies the size variables are considered to minimize the structural weight, so in this paper for better judgment the size optimizing is performed. The modulus of elasticity is $30,450 \mathrm{ksi}(210000 \mathrm{MPa})$ and the material density is $0.288 \mathrm{lb} / \mathrm{in}^{3}\left(7971.810 \mathrm{~kg} / \mathrm{m}^{3}\right)$. The yield stress of steel is taken as $58.0 \mathrm{ksi}$ (400 MPa). The dome is considered to be subjected to vertical loading at all the unsupported joints, these loads are taken as $-13.49 \mathrm{kips}(-60 \mathrm{kN})$ at node $1,-6.744 \mathrm{kips}(-$ $30 \mathrm{kN})$ at nodes 2 through 14 , and $-2.248 \mathrm{kips}(-10 \mathrm{kN})$ at the rest of the nodes. The minimum cross-sectional area of all members is $0.775 \mathrm{in}^{2} .\left(2 \mathrm{~cm}^{2}\right)$ The constraints are considered as:

(1) Stress constraints (according to the AISC ASD (1989)) [26]

$$
\begin{cases}\sigma_{i}^{+}=0.6 F_{y} & \text { for } \sigma_{i} \geq 0 \\ \sigma_{i}^{-} & \text {for } \sigma_{i}<0\end{cases}
$$




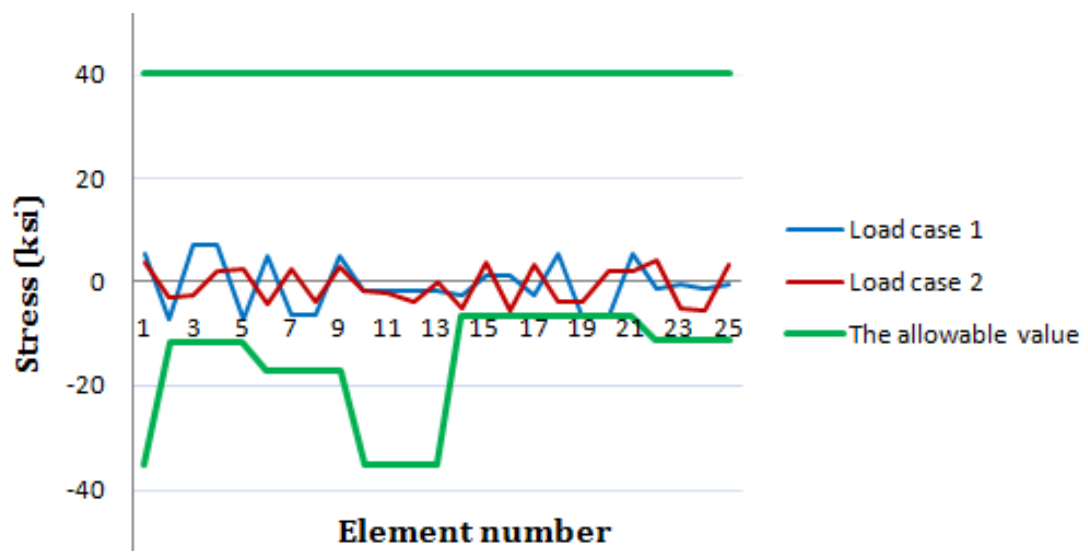

Fig. 6. Comparison of the allowable and existing stresses in the elements of the 25-bar space truss using HRPSO.
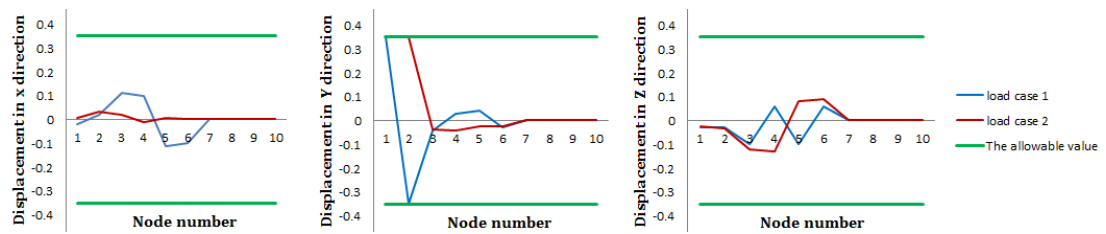

Fig. 7. Comparison of the allowable and existing displacements for the nodes of the 25-bar space truss using HRPSO.

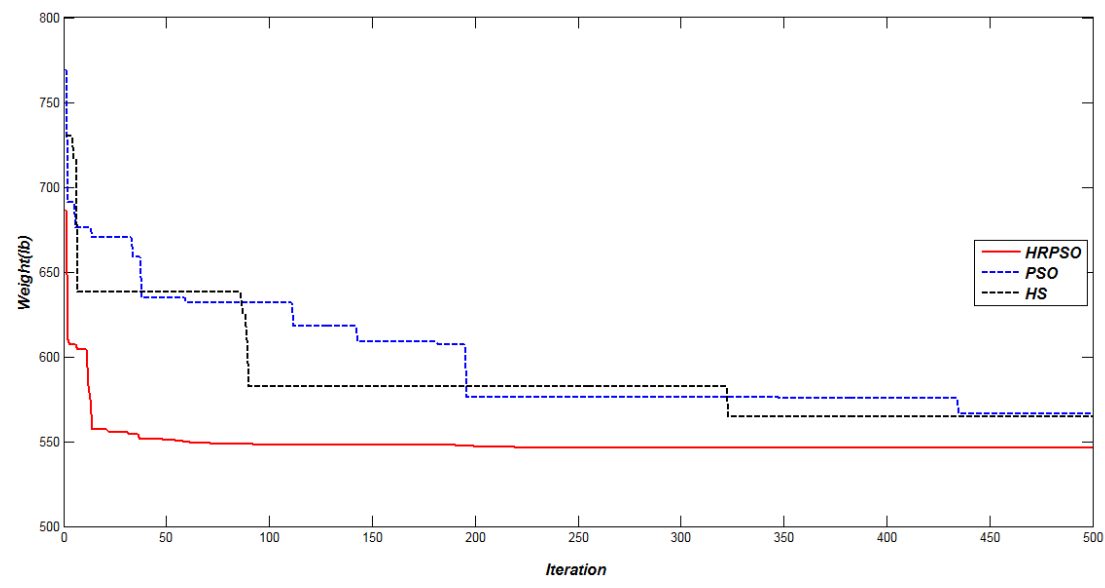

Fig. 8. Comparison of the convergence rates between the three algorithms for the 25-bar space truss structure.

Tab. 4. Optimal design comparison for the 25-bar space truss.

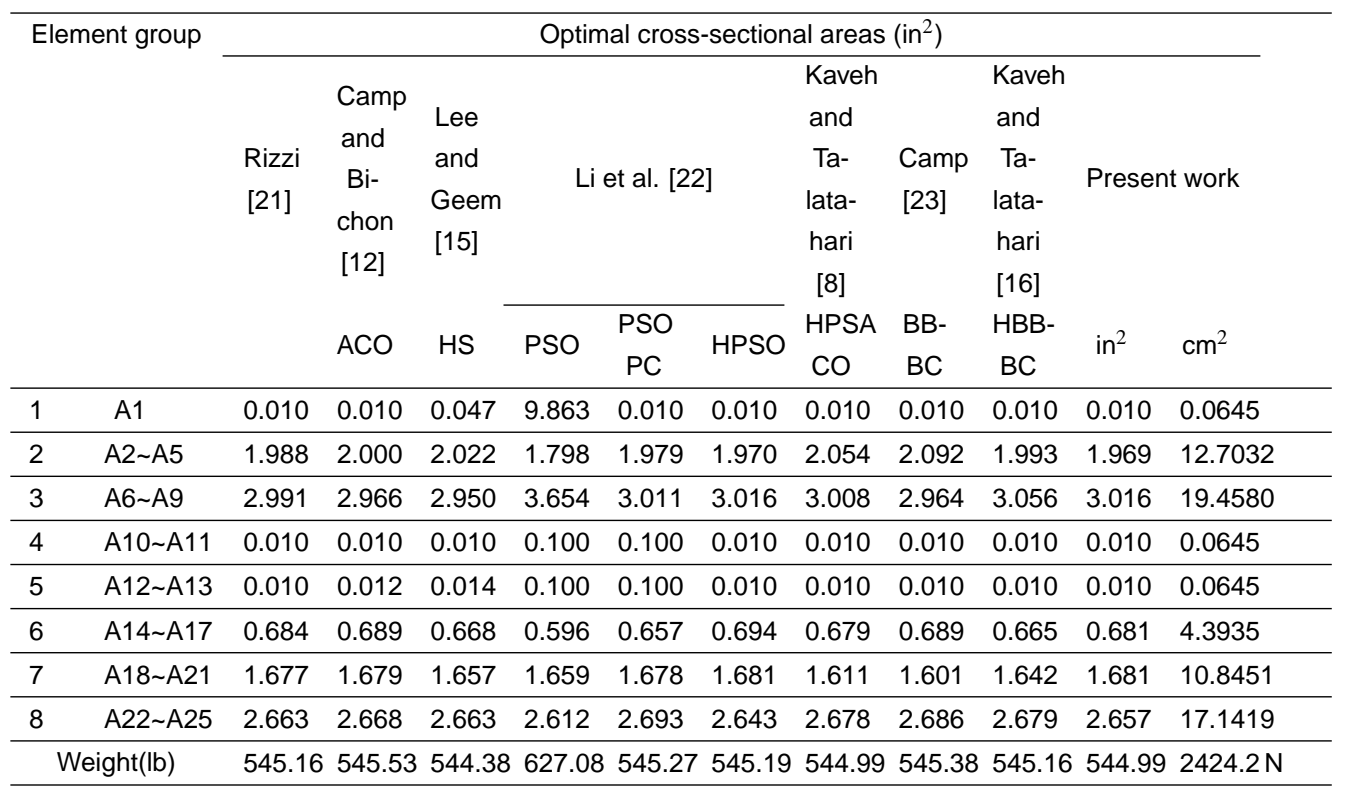




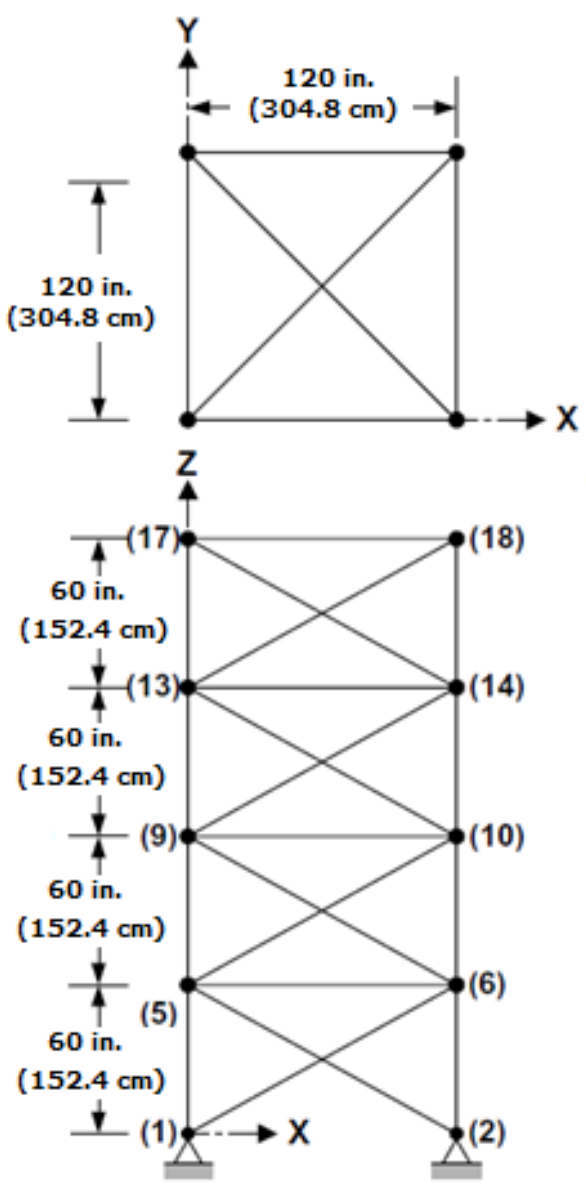

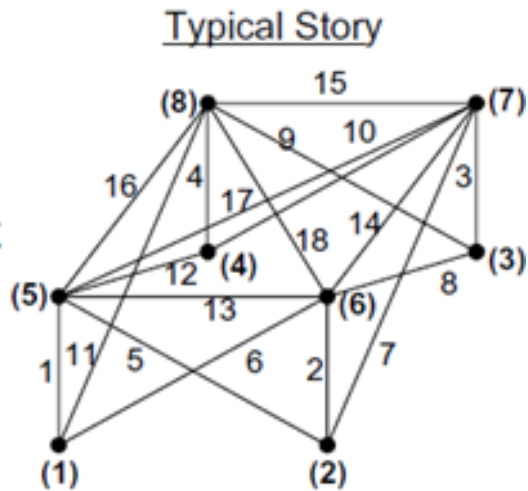

Element and node numbering system

Fig. 9. A 72-bar spatial truss.

Tab. 5. Loading conditions for the 72-bar spatial truss.

\begin{tabular}{|c|c|c|c|c|c|c|}
\hline \multirow[t]{2}{*}{ Node } & \multicolumn{3}{|c|}{ Case 1} & \multicolumn{3}{|c|}{ Case 2} \\
\hline & $\begin{array}{c}P_{X} \\
\text { kips }(\mathrm{kN})\end{array}$ & $\begin{array}{c}P_{Y} \\
\text { kips }(\mathrm{kN})\end{array}$ & $\begin{array}{c}P_{Z} \\
\text { kips }(\mathrm{kN})\end{array}$ & $\begin{array}{c}P_{X} \\
\text { kips }(\mathrm{kN})\end{array}$ & $\begin{array}{c}P_{Y} \\
\text { Kips }(k N)\end{array}$ & $\begin{array}{c}P_{Z} \\
\text { kips }(\mathrm{kN})\end{array}$ \\
\hline 17 & $5.0(22.25)$ & $5.0(22.25)$ & $\begin{array}{c}-5.0 \\
(22.25)\end{array}$ & 0. & 0. & $\begin{array}{c}-5.0 \\
(22.25)\end{array}$ \\
\hline 18 & 0.0 & 0.0 & 0.0 & 0.0 & 0.0 & $\begin{array}{c}-5.0 \\
(22.25) \\
\end{array}$ \\
\hline 19 & 0.0 & 0.0 & 0.0 & 0.0 & 0.0 & $\begin{array}{c}-5.0 \\
(22.25) \\
\end{array}$ \\
\hline 20 & 0.0 & 0.0 & 0.0 & 0.0 & 0.0 & $\begin{array}{c}-5.0 \\
(22.25)\end{array}$ \\
\hline
\end{tabular}

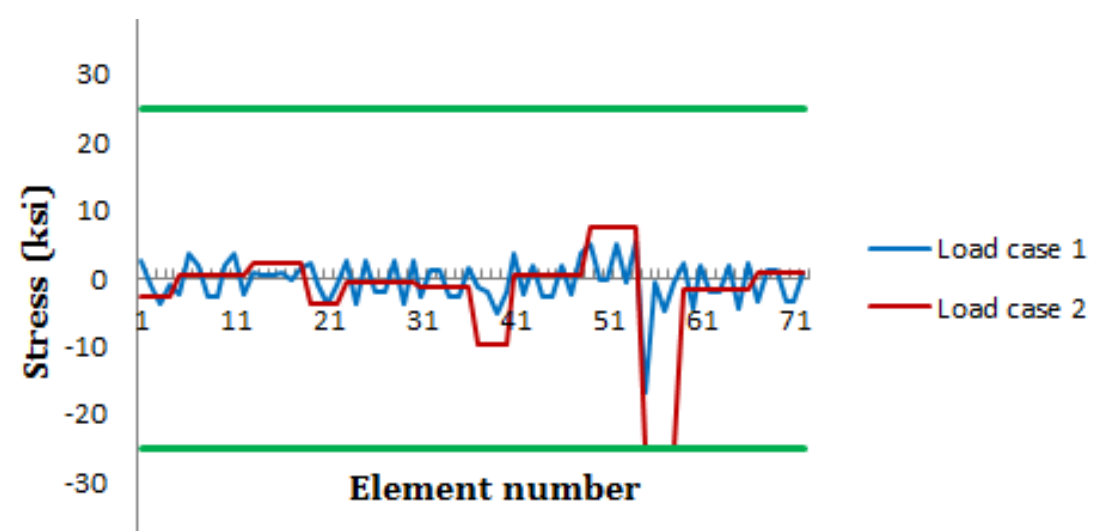

Fig. 10. Comparison of the allowable and existing stresses in the elements of the 72-bar space truss using HRPSO (Case 2). 
Tab. 6. Optimal design comparison for the 72-bar space truss (Case 1).

\begin{tabular}{|c|c|c|c|c|c|c|c|c|c|c|c|}
\hline \multicolumn{2}{|c|}{ Element group } & \multicolumn{10}{|c|}{ Optimal cross-sectional areas $\left(\right.$ in $\left.^{2}\right)$} \\
\hline & & \multicolumn{2}{|c|}{ Khan and } & \multirow{2}{*}{$\begin{array}{l}\text { Camp } \\
\text { and } \\
\text { Bichon } \\
12\end{array}$} & \multirow{2}{*}{$\begin{array}{c}\text { Lee } \\
\text { and } \\
\text { Geem } \\
15\end{array}$} & \multirow{2}{*}{$\begin{array}{l}\begin{array}{c}\text { Perez } \\
\text { and }\end{array} \\
\text { Behdinan } \\
14\end{array}$} & \multirow{2}{*}{$\begin{array}{l}\text { Camp } \\
23 .\end{array}$} & \multirow{2}{*}{$\begin{array}{l}\text { Kaveh } \\
\text { and } \\
\text { Talata- } \\
\text { hari } \\
{[16}\end{array}$} & \multirow{2}{*}{$\begin{array}{l}\text { Kaveh } \\
\text { and } \\
\text { Khayata- } \\
\text { zad } \\
20 .\end{array}$} & \multicolumn{2}{|c|}{ Present } \\
\hline & & Willmert & t 24. & & & & & & & work & \\
\hline & & & & $\mathrm{ACO}$ & HS & PSO & $\begin{array}{l}\text { BB- } \\
\text { BC }\end{array}$ & $\begin{array}{l}\text { HBB- } \\
\text { BC }\end{array}$ & RO & $i^{2}$ & $\mathrm{~cm}^{2}$ \\
\hline & & $\eta=0.1$ & $\eta=0.15$ & & & & & & & & \\
\hline 1 & $\mathrm{~A} 1 \sim \mathrm{A} 4$ & 1.793 & 1.859 & 1.948 & 1.790 & 1.7427 & 1.8577 & 1.9042 & 1.836490 & 1.83100 & 11.812 \\
\hline 2 & $\mathrm{~A} 5 \sim \mathrm{A} 12$ & 0.522 & 0.526 & 0.508 & 0.521 & 0.5185 & 0.5059 & 0.5162 & 0.502096 & 0.50954 & 3.2873 \\
\hline 3 & $\mathrm{~A} 13 \sim \mathrm{A} 16$ & 0.100 & 0.100 & 0.101 & 0.100 & 0.1000 & 0.1000 & 0.1000 & 0.100007 & 0.10000 & 0.6452 \\
\hline 4 & $\mathrm{~A} 17 \sim \mathrm{A} 18$ & 0.100 & 0.100 & 0.102 & 0.100 & 0.1000 & 0.1000 & 0.1000 & 0.100390 & 0.10000 & 0.6452 \\
\hline 5 & $\mathrm{~A} 19 \sim \mathrm{A} 22$ & 1.208 & 1.253 & 1.303 & 1.229 & 1.3079 & 1.2476 & 1.2582 & 1.252233 & 1.26539 & 8.1638 \\
\hline 6 & A23 A30 & 0.521 & 0.524 & 0.511 & 0.522 & 0.5193 & 0.5269 & 0.5035 & 0.503347 & 0.50610 & 3.2652 \\
\hline 7 & A31 A34 & 0.100 & 0.100 & 0.101 & 0.100 & 0.1000 & 0.1000 & 0.1000 & 0.100176 & 0.10000 & 0.6452 \\
\hline 8 & A35 A36 & 0.100 & 0.100 & 0.100 & 0.100 & 0.1000 & 0.1012 & 0.1000 & 0.100151 & 0.10000 & 0.6452 \\
\hline 9 & A37 A40 & 0.623 & 0.581 & 0.561 & 0.517 & 0.5142 & 0.5209 & 0.5178 & 0.572989 & 0.51550 & 3.3258 \\
\hline 10 & $\mathrm{~A} 41 \sim \mathrm{A} 48$ & 0.523 & 0.527 & 0.492 & 0.504 & 0.5464 & 0.5172 & 0.5214 & 0.549872 & 0.53250 & 3.4355 \\
\hline 11 & A49 A52 & 0.100 & 0.100 & 0.100 & 0.100 & 0.1000 & 0.1004 & 0.1000 & 0.100445 & 0.10000 & 0.6452 \\
\hline 12 & A53 A54 & 0.196 & 0.158 & 0.107 & 0.101 & 0.1095 & 0.1005 & 0.1007 & 0.100102 & 0.10019 & 0.6464 \\
\hline 13 & A55 A58 & 0.149 & 0.152 & 0.156 & 0.156 & 0.1615 & 0.1565 & 0.1566 & 0.157583 & 0.15611 & 1.0072 \\
\hline 14 & A59 A66 & 0.570 & 0.561 & 0.550 & 0.547 & 0.5092 & 0.5507 & 0.5421 & 0.522220 & 0.55790 & 3.5993 \\
\hline 15 & $\mathrm{~A} 67 \sim \mathrm{A} 70$ & 0.443 & 0.438 & 0.390 & 0.442 & 0.4967 & 0.3922 & 0.4132 & 0.435582 & 0.41360 & 2.6684 \\
\hline 16 & A71 A72 & 0.519 & 0.532 & 0.592 & 0.590 & 0.5619 & 0.5922 & 0.5756 & 0.597158 & 0.55304 & 3.5680 \\
\hline & t (lb) & 381.72 & 387.67 & 380.24 & 379.27 & 381.91 & 379.85 & 379.66 & 380.458 & 379.688 & $1689 \mathrm{~N}$ \\
\hline
\end{tabular}

Tab. 7. Optimal design comparison for the 72-bar space truss (Case 2).

\begin{tabular}{|c|c|c|c|c|}
\hline \multicolumn{2}{|c|}{ Element group } & \multicolumn{3}{|c|}{ Optimal cross-sectional areas $\left(\mathrm{in}^{2}\right)$} \\
\hline & & \multirow{2}{*}{$\begin{array}{c}\text { Lee and Geem 15 } \\
\text { HS }\end{array}$} & \multicolumn{2}{|c|}{ Present work } \\
\hline & & & $i^{2}$ & $\mathrm{~cm}^{2}$ \\
\hline 1 & $\mathrm{~A} 1 \sim \mathrm{A} 4$ & 1.963 & 1.88900 & 12.1871 \\
\hline 2 & A5 A12 & 0.481 & 0.53020 & 3.4206 \\
\hline 3 & $\mathrm{~A} 13 \sim \mathrm{A} 16$ & 0.010 & 0.01000 & 0.0645 \\
\hline 4 & A17 A18 & 0.011 & 0.01000 & 0.0645 \\
\hline 5 & A19 A22 & 1.233 & 1.31480 & 8.4826 \\
\hline 6 & A23 A30 & 0.506 & 0.50929 & 3.2857 \\
\hline 7 & A31 A34 & 0.011 & 0.01000 & 0.0645 \\
\hline 8 & A35 A36 & 0.012 & 0.01000 & 0.0645 \\
\hline 9 & A37 A40 & 0.538 & 0.52950 & 3.4161 \\
\hline 10 & A41 A48 & 0.533 & 0.52634 & 3.3957 \\
\hline 11 & A49 A52 & 0.010 & 0.01000 & 0.0645 \\
\hline 12 & A53 A54 & 0.167 & 0.08941 & 0.5768 \\
\hline 13 & A55 A58 & 0.161 & 0.16927 & 1.0921 \\
\hline 14 & A59 A66 & 0.542 & 0.52700 & 3.4000 \\
\hline 15 & A67 A70 & 0.478 & 0.42545 & 2.7448 \\
\hline 16 & A71 A72 & 0.551 & 0.59162 & 3.8169 \\
\hline \multicolumn{2}{|c|}{ Weight (lb) } & 364.33 & 363.943 & $1618.9 \mathrm{~N}$ \\
\hline
\end{tabular}
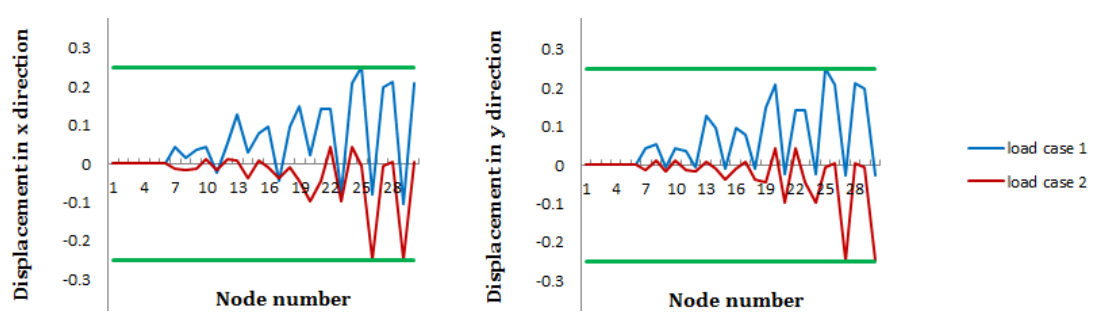

Fig. 11. Comparison of the allowable and existing displacements for the nodes of the 72-bar space truss using HRPSO (Case 2). 


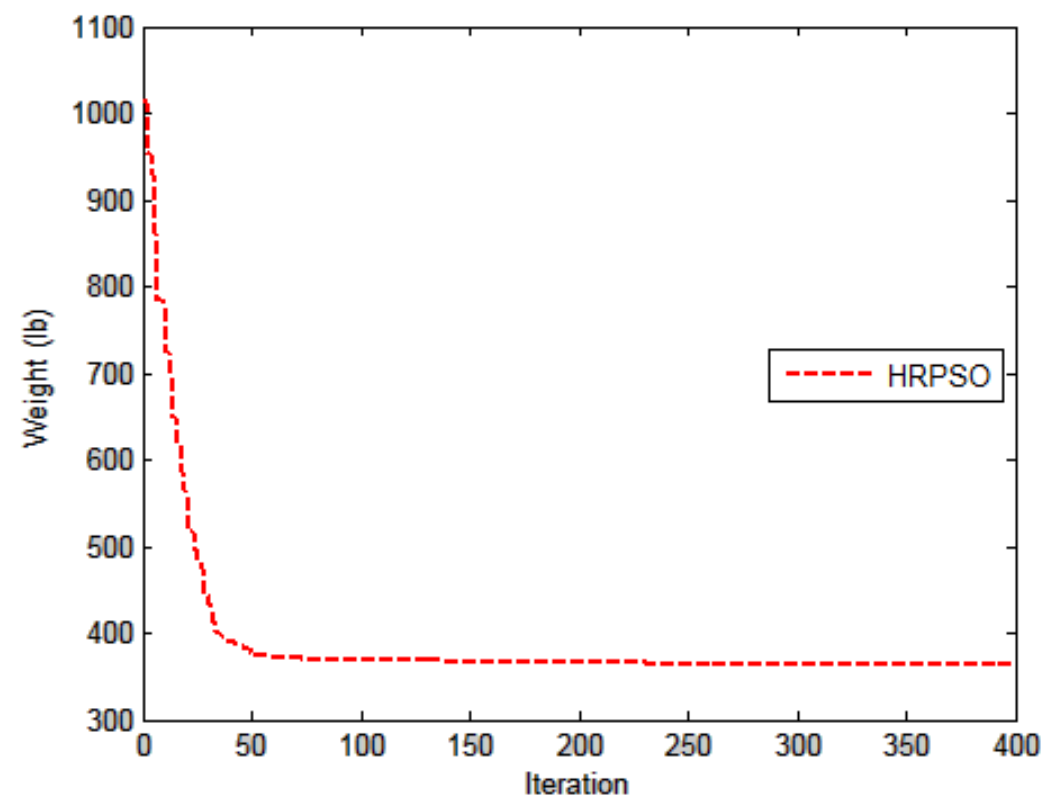

Fig. 12. Convergence rate for the 72-bar spatial truss structure using HRPSO (Case 2).

Where $\sigma_{i}^{-}$is calculated according to the slenderness ratio:

$$
\sigma_{i}^{-}= \begin{cases}{\left[\left(1-\frac{\lambda_{i}^{2}}{2 C_{C}^{2}}\right) F_{y}\right] /\left(\frac{5}{3}+\frac{3 \lambda_{i}}{8 C_{C}}-\frac{\lambda_{i}^{3}}{8 C_{C}^{3}}\right)} & \text { for } \lambda_{i}<C_{C} \\ \frac{12 \pi^{2} E}{23 \lambda_{i}^{2}} & \text { for } \lambda_{i} \geq C_{C}\end{cases}
$$

Where $E=$ the modulus of elasticity; $F_{y}=$ the yield stress of steel; $C c=$ the slenderness ratio $\left(\lambda_{i}\right)$ dividing the elastic and inelastic buckling regions $\left(C_{C}=\sqrt{2 \pi^{2} E / F_{y}}\right) ; \lambda_{i}$ the slenderness ratio $\left(\lambda_{i}=k L_{i} / r_{i}\right) ; k=$ the effective length factor; $L_{i}=$ the member length; and $r_{i}=$ the radius of gyration. On the other hand, the radius of gyration $\left(r_{i}\right)$ can be expressed in terms of crosssectional areas, i.e., $r_{i}=a A_{i}^{b}[27 \mid$, Here, $a$ and $b$ are the constants depending on the types of sections adopted for the members such as pipes, angles, and tees. In this example, pipe sections ( $a=0.4993$ and $b=0.6777$ ) were adopted for bars and four cases of constraints were considered:

Case 1: with stress constraints and no displacement constraints

Case 2: stress constraints and displacement limitations of \pm 0.1969 in $( \pm 5 \mathrm{~mm})$ are imposed on all nodes in $x$ - and $y$ directions.

Case 3: no stress constraints but displacement limitations of \pm 0.1969 in $( \pm 5 \mathrm{~mm})$ imposed on all nodes in z-directions.

Case 4: all constraints explained above

Tab. 8 gives the best solution and the corresponding weights for all cases. HRPSO needs nearly 16000 function evaluations to reach a solution which is less than 35,000 and 19850 for HS [15] and RO [20] respectively. Fig. 14] to Fig. 19 compare the allowable and existing stress and displacement constraint values of the HRPSO resulted in four cases. By analyzing these charts, it can be inferred that in Case 1, the stress constraints of some elements in the 2nd, 4th and 7th groups are active. In Case 2, the stress constraints of some elements in the 2nd, 4 th and 7 th groups and the displacement of node 26 in y direction are active. The maximum value for displacement in the $\mathrm{x}$ direction is $0.1835 \mathrm{in}(0.4661 \mathrm{~cm})$ and the maximum displacement in the y direction is 0.1967 in $(0.4996 \mathrm{~cm})$. The active constraints for Case 3 are the displacements of the node 6 and node $10 \mathrm{in} \mathrm{z} \mathrm{di-}$ rections which is 0.1969 in $(0.5001 \mathrm{~cm})$. In Case 4 , the stresses in the elements of the 7th group and the displacements of the 2nd to 13 th nodes in $\mathrm{z}$ directions affect the results. 

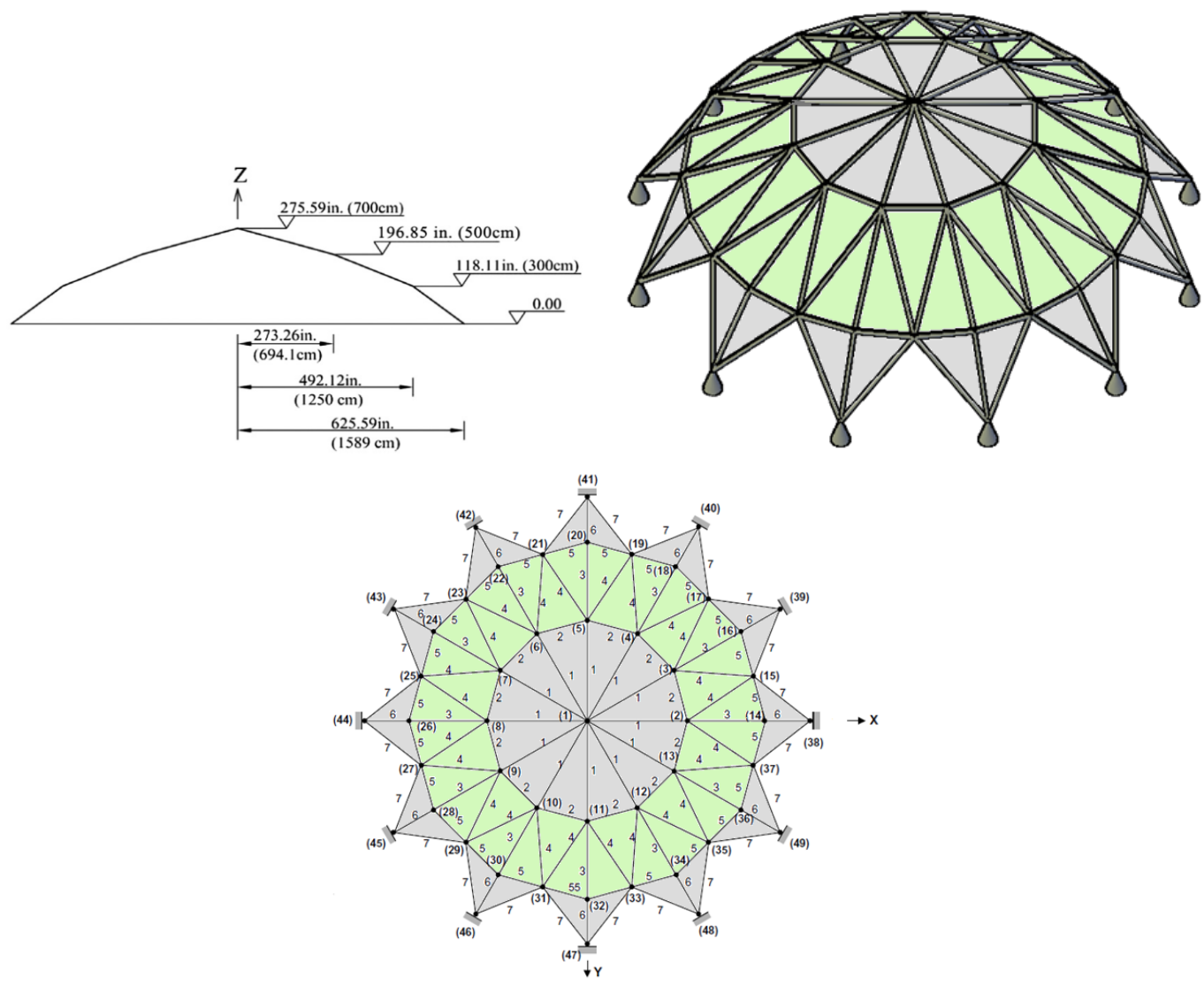

Fig. 13. A 120-bar dome truss.

Tab. 8. Optimal design comparison for the 120-bar dome truss (Case 1).

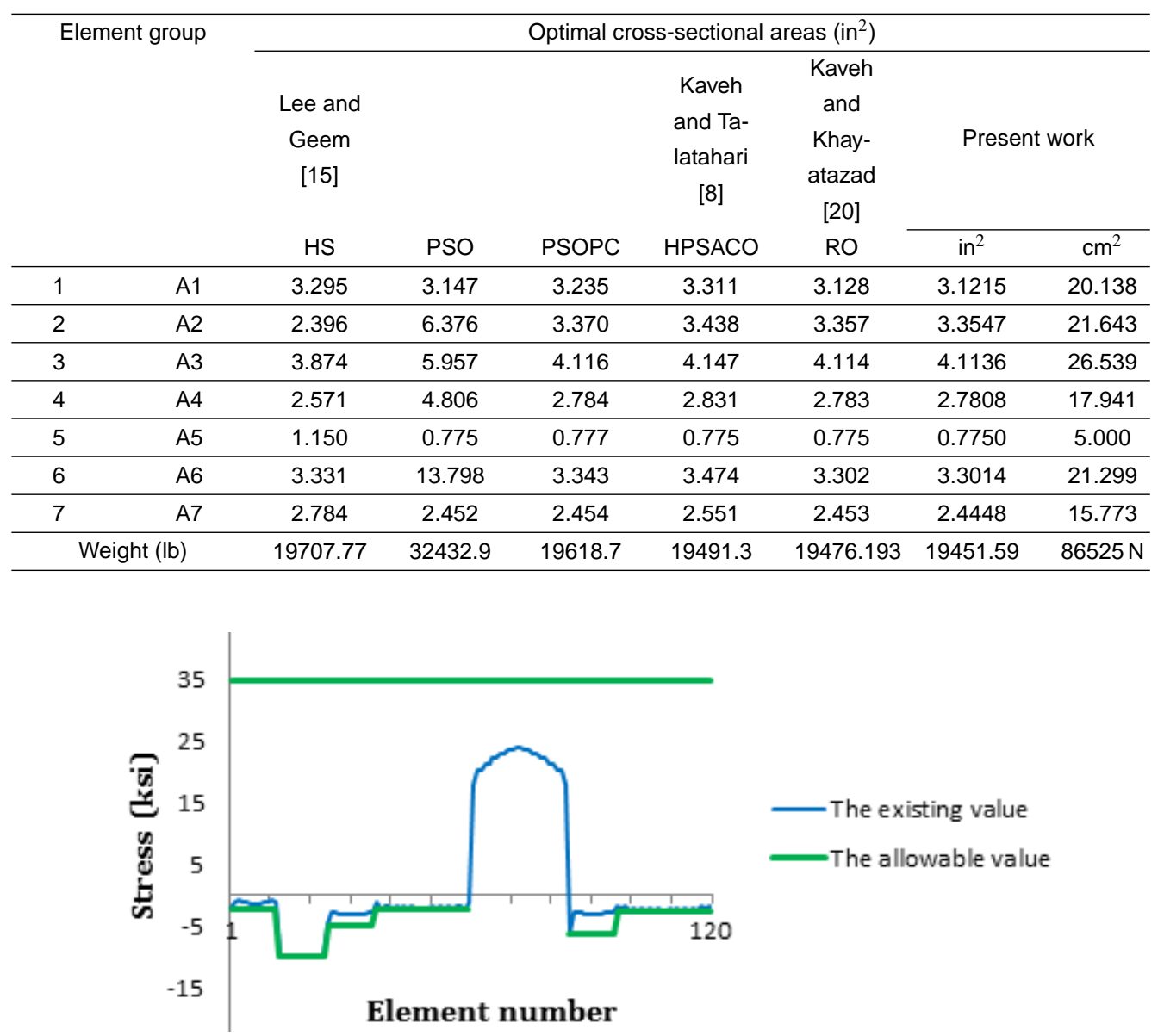

Fig. 14. Comparison of the allowable and existing stresses in the elements of the 120-bar dome truss using HRPSO (Case 1). 
Tab. 9. Optimal design comparison for the 120-bar dome truss (Case 2).

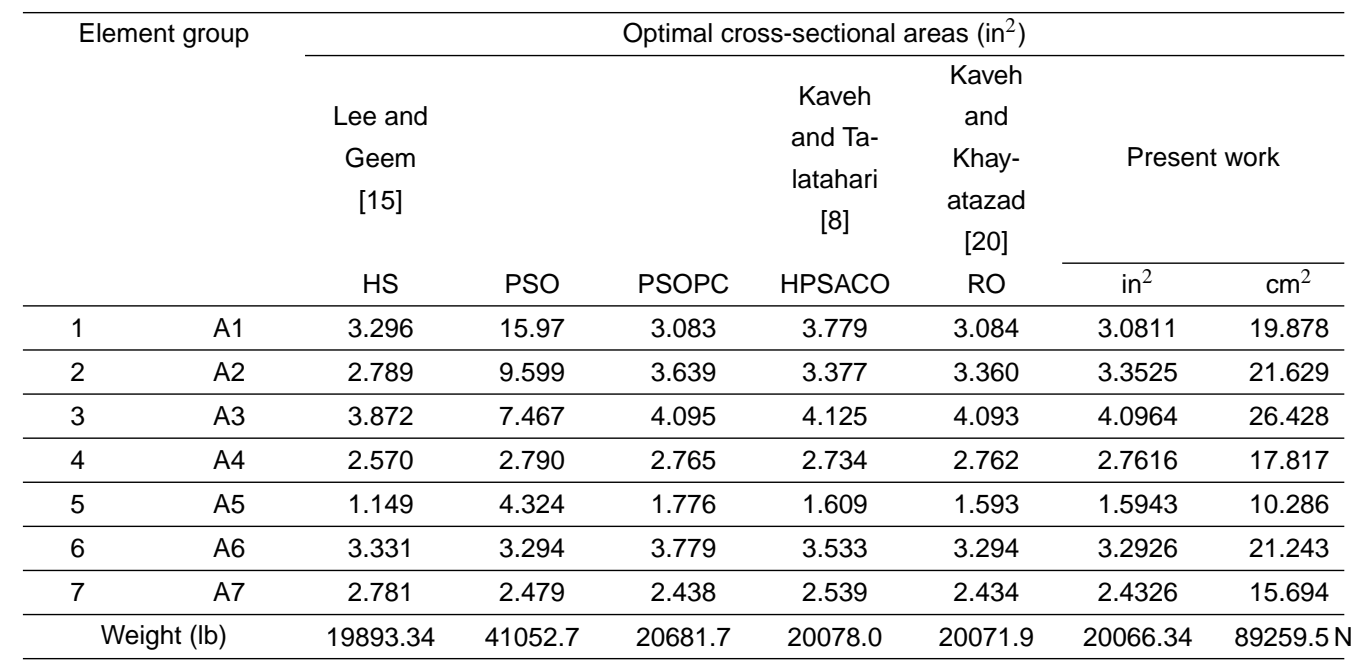

Tab. 10. Optimal design comparison for the 120-bar dome truss (Case 3).

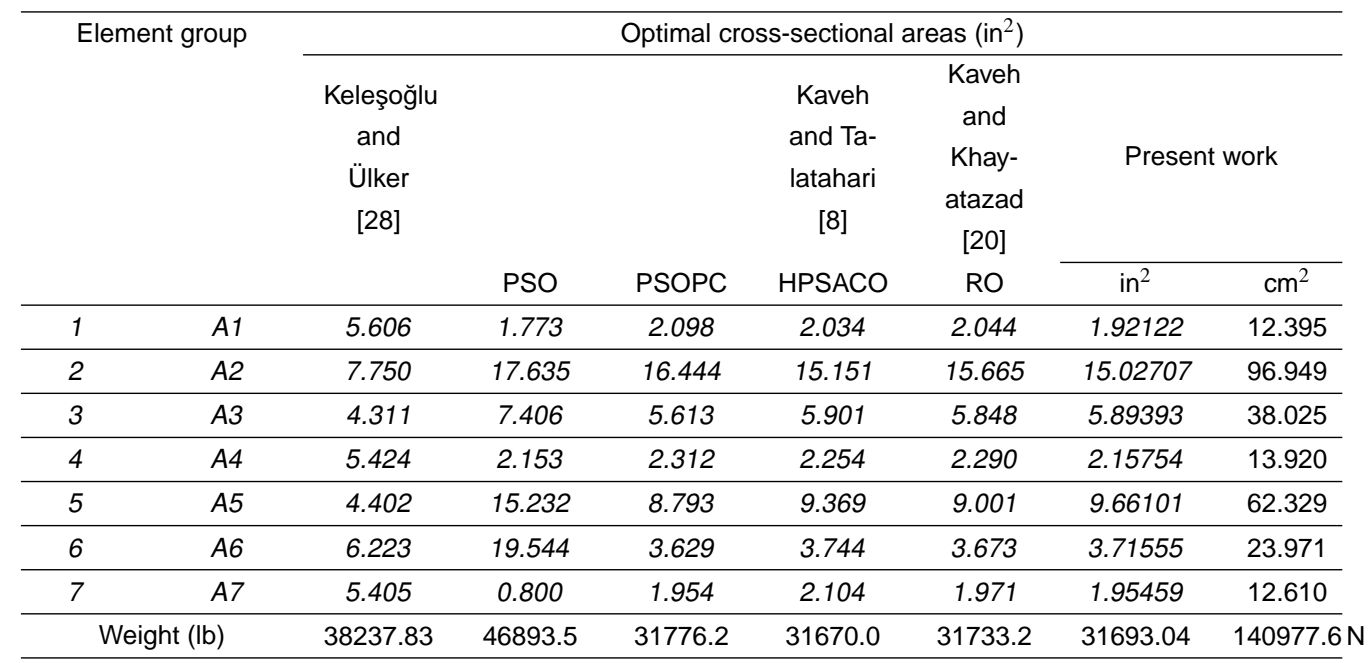

Tab. 11. Optimal design comparison for the 120-bar dome truss (Case 4).

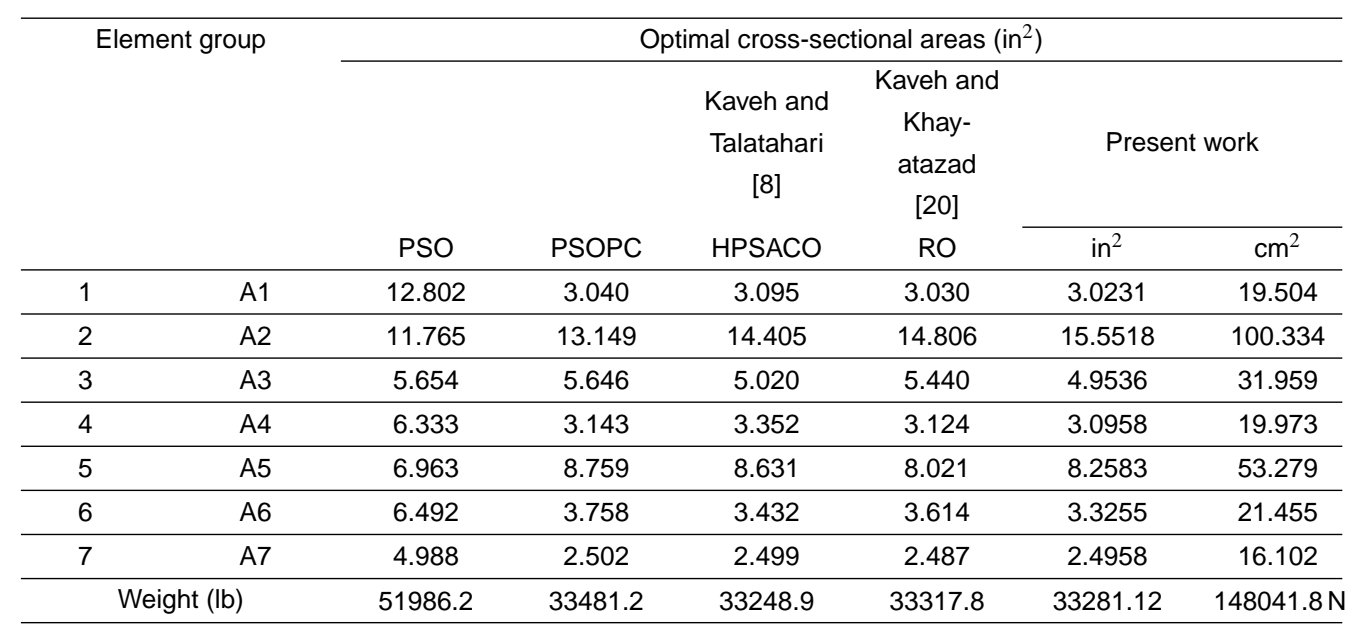




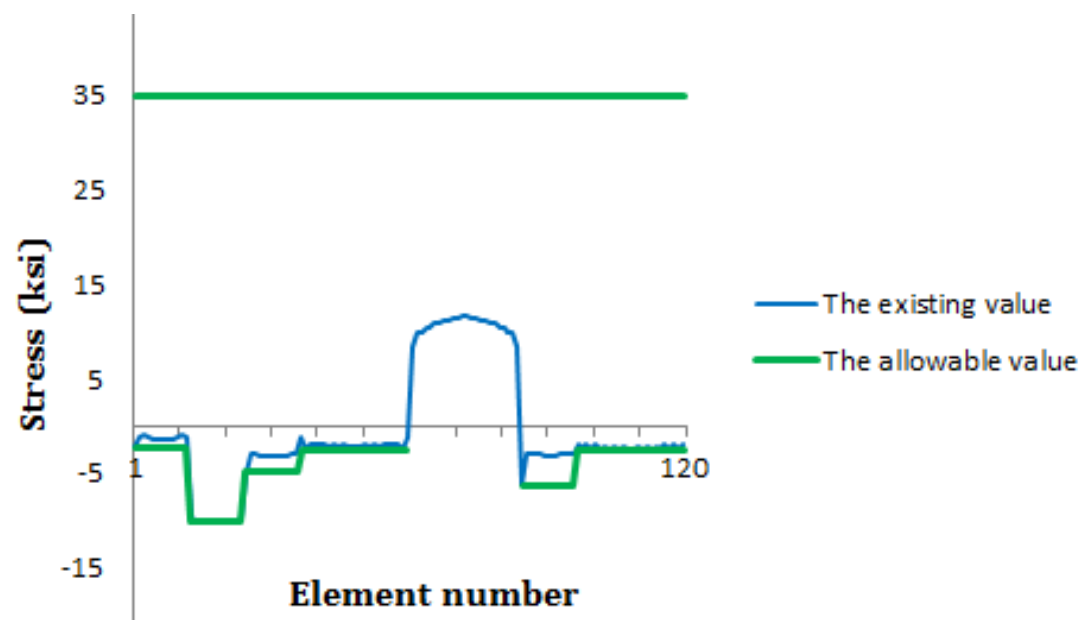

Fig. 15. Comparison of the allowable and existing stresses in the elements of the 120-bar dome truss using HRPSO (Case 2).
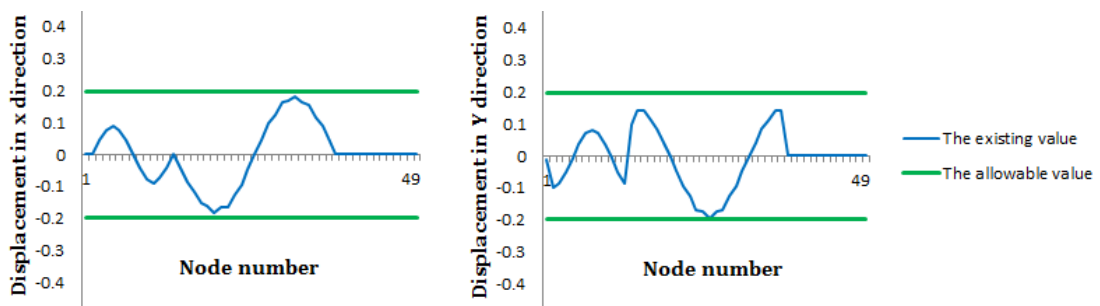

Fig. 16. Comparison of the allowable and existing displacements for the 120-bar dome truss using HRPSO (Case 2).

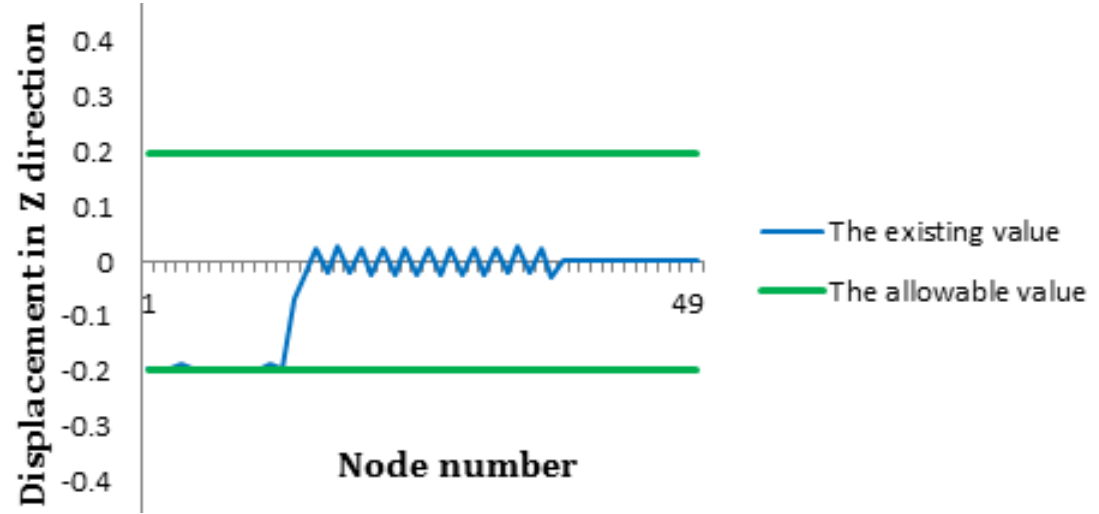

Fig. 17. Comparison of the allowable and existing displacements for the 120-bar dome truss using HRPSO (Case 3).

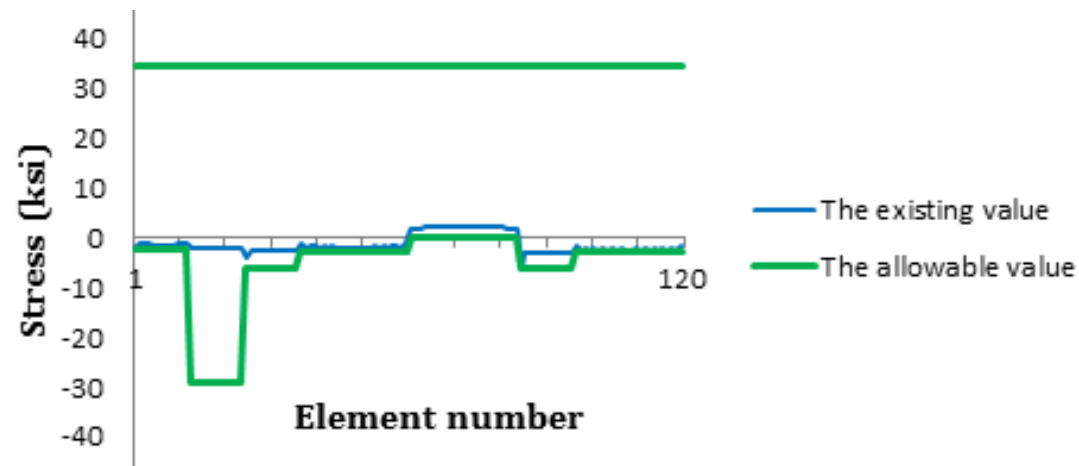

Fig. 18. Comparison of the allowable and existing stresses in the elements of the 120-bar dome truss using HRPSO (Case 4).
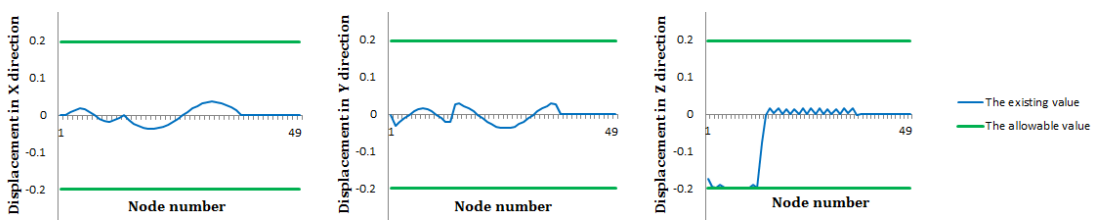

Fig. 19. Comparison of the allowable and existing displacements for the 120-bar dome truss using HRPSO (Case 4). 


\subsection{A 200-bar planar truss}

Fig. 20 shows the 200-bar planar truss which all members are made of steel: the material density and modulus of elasticity are $0.283 \mathrm{lb} / \mathrm{in}^{3}\left(7933.410 \mathrm{~kg} / \mathrm{m}^{3}\right)$ and 30,000 ksi (206000 MPa), respectively. This truss is subjected to constraints only on stress limitations of $\pm 10 \mathrm{ksi}$ ( $68.95 \mathrm{MPa})$. The minimum admissible cross-sectional area is $0.1 \mathrm{in}^{2} . \quad\left(0.6452 \mathrm{~cm}^{2}\right)$ There are three loading conditions: (1) $1.0 \mathrm{kip}(4.45 \mathrm{kN})$ acting in the positive $\mathrm{x}$ - direction at nodes $1,6,15,20,29,43,48,57,62$, and 71; (2) 10 kips $(44.5 \mathrm{kN})$ acting in the negative y-direction at nodes 1 , $2,3,4,5,6,8,10,12,14,15,16,17,18,19,20,22,24, \ldots, 71,72$, 73, 74 and 75; and (3) Conditions (1) and (2) acting together. The 200 members of this truss are divided into 29 groups, as shown in Tab. 12 .

The HRPSO algorithm found the best weight as $25451.95 \mathrm{lb}$ after 34000 function evaluations. A comparison to other references with respect to the cross-sectional area of each group and the final weight reached for the Two-hundredbar planar truss is shown in the Tab. 12. In some studies the allowable stresses have been considered as approximately $10.4 \mathrm{ksi}$ $(46.26 \mathrm{kN})$, In this case the HRPSO algorithm found the best weight as $24853.5 \mathrm{lb}(110553.9 \mathrm{~N})$ and the solution vector was: $(0.1058,0.8925,0.178,0.1049,1.879,0.3052,0.1006$, 2.9898, 0.2781, 3.9236, 0.4434, 0.103, 5.2836, 0.1566, 6.1959, $0.572,0.1005,7.8522,0.1197,8.6529,0.6757,0.1519,10.3116$, $0.3816,11.284,0.9516,7.0692,10.7735,13.0702)$.

\section{CONCLUDING REMARKS}

In this paper the recently developed metaheuristic populationbased search "RO" is mixed with PSO and HS [29]. In HRPSO, the PSO acts as the main engine of the algorithm, and origin making in $\mathrm{RO}$ boosts the movement vector of the particles and improve the exploration On the other hand, the HS is used as an auxiliary tool for enhancing the local search and better exploitation Beyond these exploration and exploitation features, HRPSO decrease some parameters which are needed in PSO.

Four truss structures are considered to verify the efficiency of the HRPSO algorithm. In comparison to other metaheuristic algorithms, the HRPSO algorithm has better performance than ACO, PSO and even better than HS and RO (in some cases).

\section{Acknowledgement}

The first author is grateful to the Iran National Science Foundation for the support. 


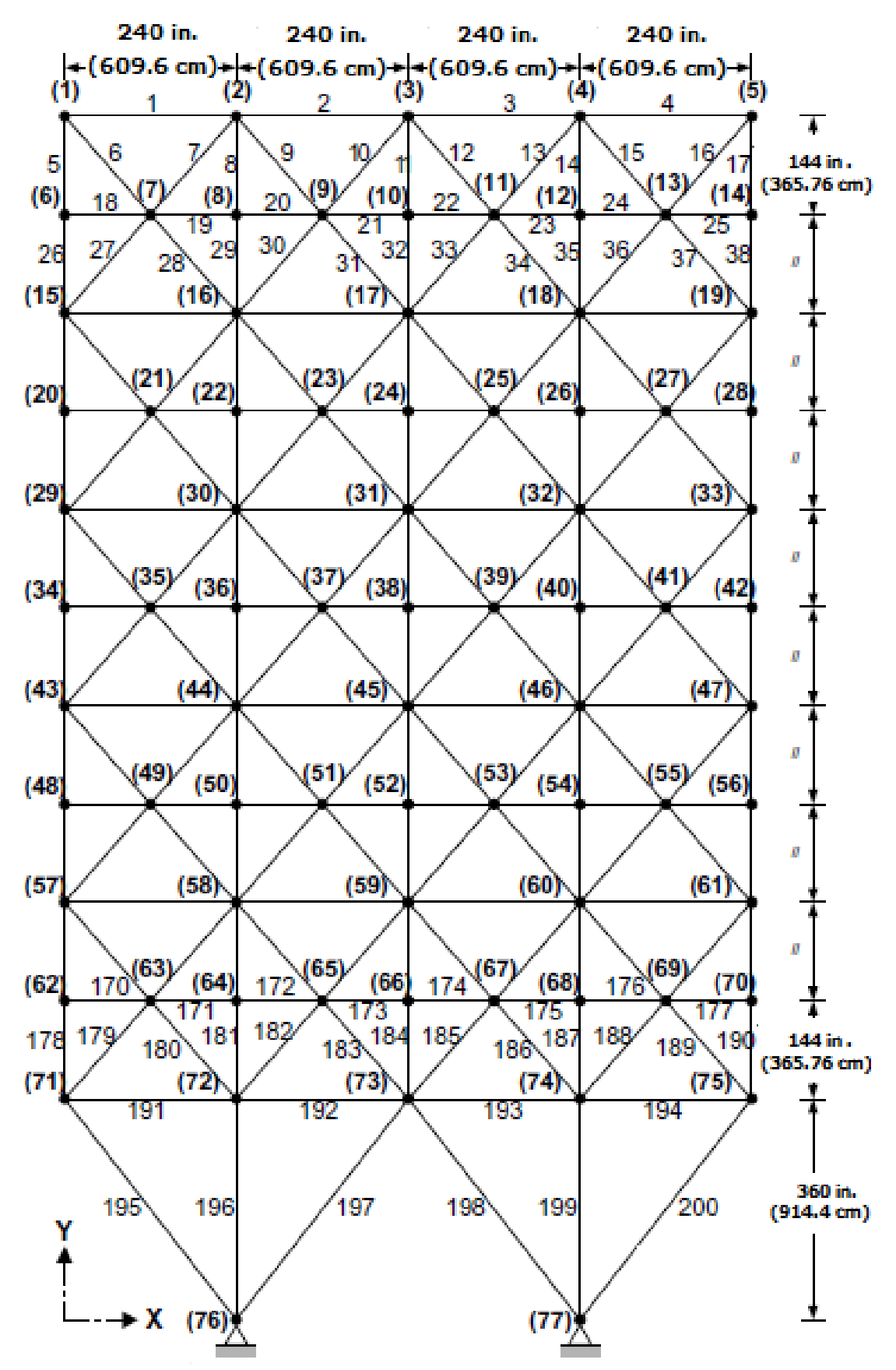

Fig. 20. A 200-bar planar truss. 
Tab. 12. Optimal design comparison for the 200-bar planar truss

\begin{tabular}{|c|c|c|c|c|c|}
\hline \multirow{3}{*}{ Group } & \multirow{3}{*}{$\begin{array}{c}\text { Variables } \\
\text { members }\left(\mathrm{A}_{i},\right. \\
\mathrm{i}=1, \ldots, 200)\end{array}$} & \multicolumn{4}{|c|}{ Optimal cross-sectional areas $\left(\mathrm{in}^{2}\right)$} \\
\hline & & \multirow{2}{*}{$\begin{array}{c}\text { Lee and Geem } \\
\qquad \begin{array}{c}16 \\
\text { HS }\end{array}\end{array}$} & \multirow[b]{2}{*}{ PSO } & \multicolumn{2}{|c|}{ Present work } \\
\hline & & & & $\mathrm{in}^{2}$ & $\mathrm{~cm}^{2}$ \\
\hline 1 & $1,2,3,4$ & 0.1253 & 0.1038 & 0.1463 & 0.9439 \\
\hline 2 & $5,8,11,14,17$ & 1.0157 & 1.0763 & 0.9440 & 6.0903 \\
\hline 3 & $19,20,21,22,23,24$ & 0.1069 & 0.1000 & 0.1000 & 0.6452 \\
\hline 4 & $\begin{array}{l}18,25,56,63,94,101 \\
132,139,170,177\end{array}$ & 0.1096 & 0.1556 & 0.1000 & 0.6452 \\
\hline 5 & $26,29,32,35,38$ & 1.9369 & 1.9468 & 1.9399 & 12.515 \\
\hline 6 & $\begin{array}{l}6,7,9,10,12,13,15,16 \\
27,28,30,31,33,34,36 \\
37\end{array}$ & 0.2686 & 0.2656 & 0.2965 & 1.9129 \\
\hline 7 & $39,40,41,42$ & 0.1042 & 0.1299 & 0.1000 & 0.6452 \\
\hline 8 & $43,46,49,52,55$ & 2.9731 & 3.0653 & 3.1050 & 20.032 \\
\hline 9 & $57,58,59,60,61,62$ & 0.1309 & 0.1221 & 0.1000 & 0.6452 \\
\hline 10 & $64,67,70,73,76$ & 4.1831 & 4.0538 & 4.1052 & 26.485 \\
\hline 11 & $\begin{array}{c}44,45,47,48,50,51,53 \\
54,65,66,68,69,71,72 \\
\quad 74,75\end{array}$ & 0.3967 & 0.3764 & 0.4030 & 2.6000 \\
\hline 12 & $77,78,79,80$ & 0.4416 & 0.1111 & 0.1926 & 1.2426 \\
\hline 13 & $81,84,87,90,93$ & 5.1873 & 4.7229 & 5.4285 & 35.022 \\
\hline 14 & $95,96,97,98,99,100$ & 0.1912 & 13.8382 & 0.1000 & 0.6452 \\
\hline 15 & $102,105,108,111,114$ & 6.241 & 5.7394 & 6.4280 & 41.470 \\
\hline 16 & $\begin{array}{l}82,83,85,86,88,89,91, \\
92,103,104,106,107, \\
109,110,112,113\end{array}$ & 0.6994 & 1.4790 & 0.5733 & 3.6987 \\
\hline 17 & $115,116,117,118$ & 0.1158 & 0.1022 & 0.1378 & 0.8890 \\
\hline 18 & $119,122,125,128,131$ & 7.7643 & 8.1039 & 7.9731 & 51.439 \\
\hline 19 & $\begin{array}{c}133,134,135,136,137 \\
138,140,143,146,149 \\
152\end{array}$ & 0.1000 & 0.1000 & 0.1000 & 0.6452 \\
\hline 20 & $140,143,146,149,152$ & 8.8279 & 9.2087 & 8.9727 & 57.888 \\
\hline 21 & $\begin{array}{c}120,121,123,124,126 \\
127,129,130,141,142, \\
144,145,147,148,150 \\
151\end{array}$ & 0.6986 & 1.0012 & 0.7073 & 4.5632 \\
\hline 22 & $153,154,155,156$ & 1.5563 & 0.1146 & 0.4200 & $2.7097 \mathrm{~N}$ \\
\hline 23 & $157,160,163,166,169$ & 10.9806 & 10.8325 & 10.867 & 70.111 \\
\hline 24 & $\begin{array}{c}171,172,173,174,175 \\
176\end{array}$ & 0.1317 & 8.3898 & 0.1000 & 0.6452 \\
\hline 25 & $178,181,184,187,190$ & 12.1492 & 11.9764 & 11.867 & 76.561 \\
\hline 26 & $\begin{array}{c}158,159,161,162,164, \\
165,167,168,179,180, \\
182,183,185,186,188, \\
189\end{array}$ & 1.6373 & 3.7262 & 1.0338 & 6.6697 \\
\hline 27 & $191,192,193,194$ & 5.0032 & 2.3484 & 6.6839 & 43.121 \\
\hline 28 & $195,197,198,200$ & 9.3545 & 8.2921 & 10.809 & 69.736 \\
\hline 29 & 196,199 & 15.0919 & 17.0625 & 13.837 & 89.270 \\
\hline \multicolumn{2}{|c|}{ Weight (lb) } & 25447.1 & 31162.1 & 25451.95 & $113215.9 \mathrm{~N}$ \\
\hline
\end{tabular}




\section{References}

1 Holland J, Adaptation in natural and artificial systems, University of Michigan Press; Ann Arbor, 1975.

2 Eberhart R, Kennedy J, A new optimizer using particle swarm theory, In: Micro Machine and Human Science, Proceedings of the IEEE Sixth International Symposium, 1995, pp. 39-43.

3 Kennedy J, Eberhart R, Particle swarm optimization, In: Neural Networks, Proceedings of the IEEE International Conference, 1995, pp. 19421948.

4 Dorigo M, Maniezzo V, Colorni A, Ant system: optimization by a colony of cooperating agents, Man, and Cybernetics, In: Part B: Cybernetics, IEEE Transactions, 1996, pp. 29-41.

5 Kaveh A, Talatahari S, A novel heuristic optimization method: charged system search, Acta Mechanica, 213(3-4), (2010), 267-289, DOI 10.1007/s00707-009-0270-4

6 Kaveh A, Khayatazad M, A new meta-heuristic method: Ray Optimization, Computers and Structures, 112, (2012), 283-294, DOI 10.1016/j.compstruc.2012.09.003

7 He S, Wu Q, Wen J, Saunders J, Paton R, A particle swarm optimizer with passive congregation, Biosystems, 78(1-3), (2004), 135-147, DOI $10.1016 /$ j.biosystems.2004.08.003

8 Kaveh A, Talatahari S, Particle swarm optimizer, ant colony strategy and harmony search scheme hybridized for optimization of truss structures, Computers and Structures, 87(5-6), (2009), 267-283, DOI 10.1016/j.compstruc.2009.01.003

9 Csébfalvi A, A hybrid meta-heuristic method for continuous engineering optimization, Periodica Polytechnica Civil Engineering, 53(2), (2009), 93100, DOI 10.3311/pp.ci.2009-2.05

10 Csébfalvi A, Multiple constrained sizing-shaping truss-optimization using ANGEL method, Periodica Polytechnica Civil Engineering, 55(1), (2011), 81-86, DOI 10.3311/pp.ci.2011-1.10

11 Toğan V, Daloğlu AT, Optimization of $3 d$ trusses with adaptive approach in genetic algorithms, Engineering Structures, 28(7), (2006), 1019-1027, DOI 10.1016/j.engstruct.2005.11.007

12 Camp C, Bichon B, Design of space trusses using ant colony optimization, Journal of Structural Engineering ASCE, 130(5), (2004), 741-751, DOI 10.1061/(ASCE)0733-9445(2004)130:5(741)

13 Schutte JF, Groenwold AA, Sizing design of truss structures using particle swarms, Structural and Multidisciplinary Optimization, 25(4), (2003), 261269, DOI 10.1007/s00158-003-0316-5

14 Perez R, Behdinan K, Particle swarm approach for structural design optimization, Computers and Structures, 85(19-20), (2007), 1579-1588, DOI 10.1016/j.compstruc.2006.10.013

15 Lee K, Geem Z, A new structural optimization method based on the harmony search algorithm, Computers and Structures, 82(9-10), (2004), 781798, DOI 10.1016/j.compstruc.2004.01.002

16 Kaveh A, Talatahari S, Size optimization of space trusses using Big Bang-Big Crunch algorithm, Computers and Structures, 87(17-18), (2009), 1129-1140, DOI 10.1016/j.compstruc.2009.04.011

17 Yang X, Engineering Optimization: An Introduction with Metaheuristic Applications, John Wiley; UK, 2010, DOI 10.1002/9780470640425

18 Shi Y, Eberhart R, A modified particle swarm optimizer, In:, pp. 69-73.

19 Lee K, Geem Z, A new meta-heuristic algorithm for continuous engineering optimization: harmony search theory and practice, Computer Method in Applied Mechanics and Engineering, 194(36-38), (2005), 3902-3933, DOI 10.1016/j.cma.2004.09.007

20 Kaveh A, Khayatazad M, Ray optimization for size and shape optimization of truss structures, Computers and Structures, 117, (2013), 82-94, DOI 10.1016/j.compstruc.2012.12.010

21 Rizzi P, Optimization of multi-constrained structures based on optimality criteria, In: Structures, Structural Dynamics, and Materials, Conference on AIAA/ASME/SAE 17th, 1976.

22 Li L, Huang Z, Liu F, Wu Q, A heuristic particle swarm optimizer for optimization of pin connected structures, Computers and Structures, 85(78), (2007), 340-349, DOI 10.1016/j.compstruc.2006.11.020

23 Camp C, Design of space trusses using Big Bang-Big Crunch optimization, Journal of Structural Engineering ASCE, 133(7), (2007), 999-1008, DOI 10.1061/(ASCE)0733-9445(2007)133:7(999)

24 Khan M, Willmert K, Thornton W, An Optimality Criterion Method for Large Scale Structures, AIAA Journal, 17(7), (1979), 753-761, DOI $10.2514 / 3.61214$

25 Soh C, Yang J, Fuzzy Controlled Genetic Algorithm Search for Shape Optimization, Journal of Computing in Civil Engineering, 10(2), (1996), 143 150, DOI 10.1061/(ASCE)0887-3801(1996)10:2(143)

26 Manual of Steel Construction-Allowable Stress Design, American Institute of Steel Construction (AISC); Chicago, IL, 1989.

27 Saka MP, Optimum Design of Pin-Jointed Steel Structures with Practical Applications, Journal of Structural Engineering, 116(10), (1990), 25992620, DOI 10.1061/(ASCE)0733-9445(1990)116:10(2599)

28 Keleşoğlu O, Ülker M, Fuzzy optimization of geometrical nonlinear space truss design, Turkish Journal of Engineering and Environmental Sciences, 29, (2005), 321-329.

29 Kaveh A, Advances in Metaheuristic Algorithms for Optimal Design of Structures, Springer Verlag; Wien, 2010. 